TP Periodica Polytechnica

Social and Management

Sciences

24(2), pp. 74-82, 2016

DOI: $10.3311 /$ PPso. 8688

Creative Commons Attribution (i)

RESEARCH ARTICLE

\section{Becoming an Entrepreneur: a Diversity of Factors, Types and Pathways}

\author{
Maria das Dores Guerreiro ${ }^{1 *}$, Ana Caetano ${ }^{1}$, Eduardo Rodrigues ${ }^{1}$, \\ Margarida Barroso ${ }^{1}$, Ana Isabel Couto ${ }^{1}$
}

Received 18 October 2015; accepted 07 January 2016

\begin{abstract}
This paper is the result of a research focused on the study of entrepreneurial patterns, contexts and experiences. Its particular objectives are the analysis of the different pathways to become an entrepreneur. On the basis of in-depth interviews to women and men entrepreneurs about their individual trajectories, a typology of access to entrepreneurship is proposed. This categorisation expresses different combinations of social factors and places particular emphasis on the effects that gender and qualifications have on the decision to become selfemployed, without neglecting the importance of socioeconomic circumstances, interpersonal networks and family relationships.
\end{abstract}

\section{Keywords}

entrepreneurship, gender, qualifications

\section{Introduction}

Entrepreneurship has become a particularly prominent phenomenon in political and media discourses as a means of overcoming the difficulties derived from the recent financial, economical and social situation in many countries. It is often presented as a way of leveraging economic development and reducing unemployment (Robson et al., 2009). This increased attention has led to the allocation of resources either material or cultural to future entrepreneurs under both state and private initiatives. It has also fostered the debate on the factors underpinning the success of individual experiences of entrepreneurship. Ultimately, the impact and reach of these initiatives depend on the knowledge produced in this respect. In order to better target the support and ensure its efficacy by knowing exactly what resources should be attributed and what skills stimulated, it is essential to identify the decisive factors that explain why individuals become entrepreneurs and why their projects are either successful or unsuccessful.

This is the background to the research project that led to the present article and whose goal was to understand the phenomenon of entrepreneurship and inform public policies accordingly. The project was entitled 'Gender, Entrepreneurship and Qualifications: trends, contexts and individual experiences' (GEQ). Its primary objective was to examine the patterns and dynamics of entrepreneurship, along with the way in which they affect the day-to-day operation of small and medium enterprises and the life paths of entrepreneurs (Guerreiro et al., 2011). We particularly sought to use the Portuguese reality, within the European framework, as a basis for understanding entrepreneurial practices from a gender perspective, while also highlighting the role played by formal qualifications and social class.

To pursue the project's goals we defined and mobilised a number of different but articulated methodological strategies that together constituted a multilevel approach. On the structural level we analysed national and European indicators on entrepreneurship, identified and explored public and private initiatives designed to promote entrepreneurial practices, and carried out a press review by collecting and analysing news items on entrepreneurship in the leading Portuguese newspapers. On
${ }^{1}$ ISCTE-Instituto Universitário de Lisboa, CIES-IUL,

Av. das Forças Armadas, 1649-026 Lisboa, Portugal

*Corresponding author, e-mail: maria.guerreiro@iscte.pt 
the organisational level we applied an online questionnaire and carried out case studies on a variety of enterprises. On the individual level we conducted in-depth interviews of women and men entrepreneurs, in order to concretely understand how structural and organisational patterns that empower and constrain the entrepreneurial initiative manifest themselves in individual experiences.

The present article focuses on this micro component of the research. We interviewed 22 people who had created small and medium-sized companies ventures and whose professional trajectories serve to illustrate different entrepreneurial profiles. Our central goal in this text is to present a typology of access to entrepreneurship that makes it possible to identify and reflect on the main factors that explain why men and women decide to become entrepreneurs. The analysis focuses thus on an initial phase in entrepreneurial processes: the decision to create one's own business and to become self-employed.

\section{How gender and qualifications matter}

We define the concept of entrepreneurship as the creation of new companies by individuals who use a variety of resources (material, symbolic, logistical) they find in their socioeconomic and cultural surroundings in order to put economic projects into practice (Aldrich, 2005; Thornton, 1999). We thus see it as a sociocultural phenomenon, which is affected by structural and contextual variables that help explain entrepreneurs' individual initiatives (Thornton et al., 2011; Tlaiss, 2014; Urbano et al., 2011). The literature on entrepreneurship often suggests that gender is a fundamental issue in research on this topic (Brush, 2008; Garcia and Welter, 2011; Kobeissi, 2010). To begin with, why do women create businesses less often than men; and when they do create them, why do they do so in quite different areas of activity? Although business creation by women has become more common in recent years, entrepreneurship as a set of practices and representations is still an institution that is characterised by deep gender differences (Arenius and Kovalainen, 2006; Marlow et al., 2009; Robichaud et al., 2007;). In general terms it is possible to highlight two axes that complement one another in explaining gender's impact on entrepreneurship. Firstly, one must pay particular attention to the dynamics of the reconciliation between paid work and family life. Female self-employment and venture creation must be looked at within the framework of the responsibilities that women traditionally assume in terms of doing unpaid work, such as domestic tasks and caring for children and other dependents. The majority of unpaid work is still a female responsibility, which means that in a context in which female activity rates are rising and increasing numbers of women are involved in selfemployment, most of them also face a 'second shift' when they get home from their paid work (Hochschild, 1989). Among other things, this means that new problems and tensions linked to the reconciliation of paid work and family life are unevenly distributed between mothers and fathers, with women displaying higher levels of stress in relation to this family/work interface (Beham et al., 2011; Crompton, 1999, 2006; Guerreiro and Rodrigues, 2009; Guerreiro et al., 2008; Lewis et al., 2011). Accumulating tasks in both spheres is an obstacle to taking on greater work-related responsibilities derived from self-employment. Secondly, while entrepreneurship is a phenomenon that can be understood by a combination of economic, social and interpersonal factors, it must also be seen as entailing a cultural dimension (Bruni et al., 2004; 2005). Specific models of masculinity are incorporated into the practices and values that are generally associated with entrepreneurship. Business cultures are produced and reproduced through a succession of contextually situated actions and interactions, and can also be interpreted in accordance with their gender markers: in types of business, in styles of management, in attitudes towards entrepreneurship, in ways of presenting the body to others (Anderson, 2008; Kanter, 1993; Powell, 2010). To this end it is necessary to pay attention to the discursive characteristics and specificities of men and women entrepreneurs: how they present themselves, what it means for them to be an entrepreneur, what makes them unique, what self-presentation rhetoric they use, and how they characterise their activity in contrast to others (Bruni et al., 2005). Within the framework of a culturalist dimension of research on male and female entrepreneurship, there must also be room to identify the potential for agency, particularly on the part of women. Through their daily practices and attitudes as business owners, they create renewed and alternative practices of entrepreneurship that are simultaneously innovative ways of constructing gender (Anderson, 2008). At this level we can find a connection with the role played by qualifications: in some cases the access of women to entrepreneurship education programmes resulted in the implementation of not only new technical and entrepreneurial skills, but also more general attitudes that lead to innovative cultural initiatives (Botha et al., 2006; Carter, 2000). The idea that entrepreneurs are born and not made is an ideology present in different types of discourse, but it has been losing ground (Kuratko, 2005; Man, 2006). The growing number of studies on this topic, which recognise the positive impact that education has on the creation of new ventures, is proof of this (Block et al., 2013; Matlay, 2008). It is also increasingly common to find the publication and dissemination of both business guides and the biographies or autobiographies of successful entrepreneurs who share their knowledge and experiences, and identify the key factors in the success of their companies. Even when the prevailing notion is that there is something innate in entrepreneurs that leads them to a given professional path, this discourse is starting to be complemented by the idea that some personal attributes can be stimulated (Kuratko, 2005). This notion is of particular importance to the integration in business of less represented social groups, such as women, via education for entrepreneurship (Botha et al., 2006). 
The research on this topic suggests a clear link between educational levels and entrepreneurial activity. A larger number of years of study means a higher probability that an individual will choose to be self-employed and will be successful in terms of growth, profits and remuneration of the new business (Block et al., 2013; Nabi and Holden, 2008; Tlaiss, 2014). In fact, the relationship between entrepreneurship and qualifications has been analysed, above all, with regard to higher education (Rasmussen, 2011; Taatila, 2010;), in line with the concerns expressed in public policies, particularly at the European level. But it is also important to bear in mind the substantial increase in the number of courses targeted at other types of population - namely those with lower levels of schooling, which characterise some segments of the Portuguese self-employed (Costa et al., 2009). Thus, an analysis of the impact that qualifications have must also incorporate this way of obtaining knowledge and skills, even if it does not result in a degree or diploma.

The bibliography on this issue suggests that there are different ways of learning to be an entrepreneur. The skills mobilised in the entrepreneurial activity are not solely acquired in school, in academic contexts or in specific training directed at entrepreneurship. It is also of key importance to consider the knowledge obtained via individuals' experiences, over the course of their life trajectories and their daily lives, in different spheres of life (particularly work) and those of family members and friends (Anderson et al., 2007; Clercq and Voronov, 2009; Kim and Aldrich, 2005; Nabi and Holden, 2008; Nabi et al., 2006).

\section{The decision to become an entrepreneur: profiles of access to entrepreneurship}

Here we analyse entrepreneurship in articulation with these two dimensions - gender and qualifications - on the basis of the qualitative component of the GEQ project. We interviewed twenty-two women and men entrepreneurs between the ages of 24 and 56 who had created a business of their own. Because it was of particular interest to understand forms of entrepreneurship in which the main protagonists were women and qualified individuals, neither the proportion of women entrepreneurs, nor that of entrepreneurs with a higher education degree (who were also the youngest among them) are representative of certain segments of the Portuguese entrepreneur population. The social origins, social class and professional experiences of the entrepreneurs we interviewed were diverse, as were their companies' areas of activity and geographic locations, albeit they were all in Portugal. In general, the firms were small or medium organisations - a feature that fits the pattern for the country's businesses. The interviews were individual and were centred around the entrepreneurs' professional trajectories, but always in articulation with life dimensions that are central to an understanding of their work-related choices, such as family and sociability.

The objective of this more focused analysis essentially entailed exploring the combination of social factors that explain individual entrepreneurial practices in a diverse set of individuals. To this end we drew up a typology of access to entrepreneurship, which is made up of five categories as shown in Table 1.

Table 1 Typology of access to entrepreneurship

\begin{tabular}{ll}
\hline 1. & Qualified entrepreneurship \\
2. Entrepreneurship for the work-life balance \\
3. Entrepreneurialisation of a previous occupation \\
4. Emancipatory entrepreneurship \\
5. $\quad$ Family entrepreneurship \\
\hline
\end{tabular}

With this analysis it is possible to explore wider processes that help understand what leads a person to become an entrepreneur.

\subsection{Qualified entrepreneurship}

Qualified entrepreneurship is characterised by entrepreneurial activity in areas that are innovative or technology-based, such as the manufacture and sale of scientific toys, fragrances, or kits for growing common mushrooms at home. The organisations led by these entrepreneurs generally have a small, agile structure and are characterised by a certain degree of informality in their processes. The firms have not yet existed for long enough to become very complex and the entrepreneur is thus generally the face of the company. To some extent these companies take on the personality of the entrepreneurs who create them, and their story is intertwined with the latter's personal path, characteristics and choices. Analysis of the main characteristics of qualified entrepreneurship allows us to identify two axes that come together to structure this type of profile. The first is based on the importance of formal qualification. These individuals have a postgraduate degree, and all of them recognised that their credentials were determinant in that they provided access to resources and both general and specialised knowledge that they as entrepreneurs could mobilise in their business trajectories. Advanced qualifications can also be crucial on various levels: the areas of activity of the companies, the types of product and services offered - which can be imbued with substantial innovatory elements -, and the agility in acquiring information or even other resources that come from insertions in networks designed to promote and support qualified entrepreneurship (Pittaway et al., 2010). The majority of these entrepreneurs had indeed resorted to national and EU policy programmes that support the acquisition of equipment, investment in internationalisation, and finding premises for the companies.

The second analytical axis cannot be dissociated from these entrepreneurs' level of qualifications, as it directly concerns the innovative or technology-based component of the products or services offered by the companies. In almost every case there is also a close relationship with research conducted in an academic environment. In some cases this was reflected not only in the 
creation of networks through which information and resources circulated continuously, but also in the pursuit of commercial activities that incorporated elements of scientific knowledge.

In the light of these two analytical axes it is also important to highlight the cross-cutting role - sometimes subtle, but not to be underestimated - played first of all by social origins, and secondly by sociability networks. Some of the interviewees in this profile have privileged social origins associated with the family accumulation of not only economic resources, but also cultural and social ones. The access to this kind of resources was determining in their decision to become entrepreneurs and to materialise their business ideas. The entrepreneurs' integration into dense networks of sociability also plays an important role in explaining access to entrepreneurial activity due to the information that circulates among colleagues or contexts linked to universities, businesses or even politics. Although during the interviews the importance of these elements tended to be downplayed by the entrepreneurs - especially those with more privileged social origins that emphasised mainly their individual qualities of persistence and proactivity - the economic, cultural and also social capitals of these individuals are crucial among the factors that help understand their professional paths. Indeed these personal 'qualities', which the interviewees talked about can be seen as personal dispositions - tenacity, autonomy, independence, creativity - whose 'creation' requires conditions that are specific because they are in short supply and are unevenly distributed. Although, as some of the individual cases also showed, these conditions are not forcibly restricted to people with privileged social origins, they are nonetheless associated with certain socialisation processes and patterns that occur in primary and secondary contexts.

\subsection{Entrepreneurship for work-life balance}

This form of entrepreneurship characterises access paths to entrepreneurial activity - in areas that in the case studies were as diverse as photography, sports and farming -, which are motivated by a search for balance in the performance of different social roles. These entrepreneurs considered that working for themselves gave them more autonomy and improved flexibility in managing the time they devoted to different life domains. The motivations underlying this professional option primarily go back to difficulties encountered in previous work experiences when it came to reconciling work and family life. This entrepreneurial profile is characterised above all by an attempt to adapt working life to family demands and responsibilities. In the other profiles we often found the reverse situation, with family and leisure time for example being organised around the work sphere.

All the entrepreneurs in this category were women - a fact that suffices to reveal the persistence of gendered dynamics in the work and family integration. This does not mean that the family issue was not also a recognised concern for the men interviewees. However, the male entrepreneurial discourse did not point to it as a key motivation for the creation of a selfemployment situation. During the interviews, problems linked to time management, caring for children and articulation with spouses' working hours appeared more often in the women's accounts - even those of the women entrepreneurs who belonged to other profiles - than in the men's narratives (Patterson and Mavin, 2009). The effect that family concerns had on the professional choices of the women from this type of entrepreneurship made itself felt in two distinct ways: via parenthood, and via conjugality.

In some cases it was the fact that they were the mothers of children aged between 1 and 10 that had led them to consider the viability of the self-employment option. Although their previous professional activities as employees were not incompatible with these women entrepreneurs' parental responsibilities, it had made it difficult for them to be involved in their children's daily lives in the ways they wanted to be. Self-employment opened up new possibilities in terms of flexibly organising their working times and family life. The fact that to a large extent they could now control the way they allocated their time enabled them to relegate their entrepreneurial projects to a secondary status whenever their children needed immediate care. It was not so much that they had more time because they worked for themselves, but rather that they could manage their time autonomously.

Although a minority, in other cases it was via conjugality and not parenthood that the option to create their own business had taken shape. Moving home due to a new conjugal relationship or a change in their husband's job led some women to leave their existing professional activities. These alterations in their lives, as they followed their husbands, had been the driving force they had needed to invest in what they had already been fuelling as professional projects for some time. Despite the unemployment situation they had momentarily found themselves in, they saw this change rather than a constraint as an opportunity to create their own business, but also for their own personal fulfilment and not a constraint, albeit without ever questioning the need to engage in a remunerated activity.

The cases that match this profile show the impact family life can have on women's career choices (Annink and den Dulk, 2012; Craig et al., 2012; Hughes, 2003). The fundamental idea of the analysis of these cases is that for these women, entrepreneurship came about as a solution to the need to simultaneously invest in work and family and not feel obliged to make a unilateral choice between one of these two spheres of life. But it is also important to note that the decision to create their own job was not made solely on the basis of family factors. The search for a balance between social roles may have been the main motive, but the choice was also enhanced by other factors, such as access to resources, the possession of specialised skills, or the existence of support networks, particularly family ones (Eddleston and Powell, 2012). 


\subsection{Entrepreneurialisation of a previous occupation}

The access to entrepreneurship in this profile derived directly from earlier occupations. I.e. these entrepreneurs have chosen to create companies in an area of activity in which they had already worked in the past, generally as employees of someone else (Guerreiro, 2001). The areas in question can be as diverse as beauty care, advertising, tourist entertainment, cutlery or printing.

In some cases the decision to become an entrepreneur results from unemployment. Faced with difficulties of getting a new job, the interviewees in this situation decided to draw up a plan for their own business as an alternative. To this end they felt that it would be of key importance to the project's success to mobilise the skills that they had already acquired over the course of their professional trajectories, thus opting to establish a business in the same area of activity.

For most of the interviewees in this entrepreneurship profile the decision to become entrepreneurs was also derived from dissatisfaction with working for someone else. Although they liked the area of activity they were in, they developed a certain discontent with the lack of autonomy in managing their daily tasks. They considered that their work was excessively formatted, with little room to propose new activities and services that would develop certain areas of the businesses they worked for. In some cases this dissatisfaction was combined with discontent with what they were being paid.

In other cases - albeit a minority in this sample group access to entrepreneurship resulted from earlier unsuccessful entrepreneurial experiences. These entrepreneurs referred to lack of experience, disagreement between partners (about the business's objectives, forms of management, and future), drawing up a business project that was not suited to the market or the Portuguese economic reality, and a shortage of material resources as factors that had been decisive in the failure of a first incursion into self-employment. However, although they had shut the businesses they had initially created, they did not see these entrepreneurial initiatives as having been entirely negative. They felt that these experiences had above all been attempts that had served as a stage to experiment. Thanks to an accumulation of skills and resources, they made it possible to define and consolidate their current entrepreneurial projects, which they had now implemented in a more consolidated way. It should also be noted that both the design and the implementation of an alternative professional plan (as a response to unemployment, dissatisfaction with working for someone else, or earlier unsuccessful business experiences) were only possible because these entrepreneurs belonged to solid networks that provided them with support (material, motivational, experience sharing), were able to mobilise resources of their own, and/or enjoyed support from public or private financial and logistic programmes. Be this as it may, regardless of the type of support they received, they all shared a capitalisation of skills that had been accumulated over the course of previous professional paths, generally lasting several years, in the same area of activity.

\subsection{Emancipatory entrepreneurship}

Emancipatory entrepreneurship characterises the access to entrepreneurial activity as a means of breaking with previous professional contexts that are experienced in a negative way. For some of these interviewees their earlier working trajectories are marked by precariousness and fairly unqualified activities; others consider that their occupations and working conditions were far from matching their professional and life ambitions. In both cases there was clear dissatisfaction with the type of tasks they had performed, the area of activity, the lack of creativity and autonomy in managing their work, and the low pay. They thus share the dissatisfaction with former experiences of paid work with some of the entrepreneurs in the entrepreneurialisation of a previous occupation's profile. However, they differ from them in one decisive respect: whereas the others continued an existing profession, these entrepreneurs had sought emancipation by making a break with their earlier work.

The entrepreneurs in this profile had already wanted to work for themselves for many years, in the belief that creating a business would be the best solution to their dissatisfaction with their existing work and the best way to improve their working conditions. Drawing up new professional plans via entrepreneurship activity was moreover associated with the redefinition of life projects. Basically, this professional conversion corresponded to an identity turning point, in the sense that they were looking for an activity that was closer to their personal interests, their stance towards life and their ambitions for the future. Their goal was to change their life conditions from the material point of view by gaining access to higher pay, but also in symbolic terms, by finding emotional wellbeing in the process of overcoming difficulties and in their ability to reformulate and achieve life goals. They ended up investing in areas in which they had accumulated not only a personal interest, but also skills: the activities entailed practices the entrepreneurs often carried out. Indeed, the people in this profile were mostly women entrepreneurs who had created firms that provided traditional services like sewing, cleaning, arts and crafts.

These entrepreneurs were solo self-employed who created micro-companies with no employees. The firms were small projects because the interviewees did not have access to resources that would enable them to achieve objectives on a larger scale. In fact, this profile includes globally those entrepreneurs whose social origins and social class positions are more disadvantaged and whose levels of schooling are lower. The implementation of their business plans had depended entirely on the grant of public support for the creation of self-employment situations. Non-access to such support programmes (financial, logistics, consultancy, training) would have directly meant giving up on 
their entrepreneurial plans. Their dependence on this type of support shows the fragility of this group of entrepreneurs and raises questions as to the sustainability of their business projects. Short-term economic changes and the end of the public support contract once the company has been formed can have negative (and determinant) effects on the continuation of the business. This was not true for the interviewees from the other profiles, who made use of similar public initiatives and resources, but complemented it with other types of resources available to them in their life contexts.

\subsection{Family entrepreneurship}

In the last profile we find the cases in which a firm was associated with a family context. This type of entrepreneurship is the result of situations in which someone carries on a business activity that already exists within their family - the production of cork or metalomechanic are examples from our case studies - but also of situations in which a company is created when relatives become business partners and/or family resources are mobilised in it.

Continuing a business created by a family member - generally a grandfather or father - facilitates entry into the labour market. Indeed, the interviewees in this profile acknowledged that even before they defined their future professional projects, they had enjoyed the security provided by the fact that they could always join the staff of the family firm. This is a central issue in their discourse, regardless of their academic paths and professional choices. However, in none of these cases was it possible to say that working in the family firm resulted from less successful experiences or difficulty in getting a job elsewhere. In fact, these entrepreneurs had taken up the family business as their own personal project and life option; and it had not acquired the status of an unwanted inheritance.

Contact with the business environment occurred very early in their lives, and they saw the history of the company and that of the family as being intertwined (Guerreiro, 1996; Howorth et al., 2010). This on-going positive connection with the family business since an early age helped incorporate a strong disposition towards entrepreneurship in these individuals, stimulating interest and developing entrepreneurial skills. The relatives who created the firm were seen as models to be followed, inasmuch as they had been successful in the construction of the family's heritage.

This group of entrepreneurs generally began working in the family firm performing subordinate tasks that enabled them to learn the concrete dynamics of the business. Later, after accumulating experience and knowledge, in some situations they even took on managerial positions, especially when the founder retired, in accordance with a succession philosophy (Guerreiro, 1996; Howorth and Ali, 2001; Zellweger et al., 2012). Some of them had already chosen their higher education course with a view to taking up a managerial post. Promotion within the company tended to be faster when the entrepreneur held a higher education degree. Their families generally welcomed this form of integration, because the skills obtained in an academic context complemented the knowledge acquired by the family through many years of experience. The fact is that the interviewees who had completed a higher-level course brought new drive to the company, particularly by investing heavily in its modernisation, accreditation and expansion, but also by bringing in new management models and defining alternative business paths.

Family entrepreneurship can also manifest itself through the association of relatives in order to begin a shared entrepreneurial project (Brannon et al., 2013; Cruz et al., 2013). Their emotional closeness and mutual trust enable them to conjugate their efforts, combine proposals and plans and mobilise resources with a view to creating and implementing a business idea. It is especially common for a family firm to arise out of conjugality, with the men often performing the management function and the women playing a role that is less visible, but nonetheless important to the dynamics involved in the creation and operation of the new company (Guerreiro, 1996). Many of these firms, being small or medium-sized, tend to have a workforce that is mostly made up of family members, such as spouses, parents, siblings, uncles, aunts, or cousins.

Here we are in the presence of a type of entrepreneurship whose outlines differ from those in the other profiles, inasmuch as these interviewees were not the ones who created the business project from the beginning. However, we felt that it was important to incorporate the family profile into the discussion about entrepreneurial factors given the proactive and decisive role these entrepreneurs had played in the current configuration of the family business, of which they had become the managers in the majority of cases. Ultimately, they had created their own project within the existing family one.

\section{Conclusions: factors of access to entrepreneurship}

In each entrepreneurial profile there is a singular articulation of factors that explains the access to entrepreneurship. These indicators combine in a different way for each category in the typology, but also for each person too. Even so, the singularity of this type of analysis is an expression of broader social dynamics and patterns, so it is possible to use the integrated examination of individual cases as a basis for identifying a relevant set of social factors that explain why, how and under what conditions a person becomes an entrepreneur. Table 2 systematises this analysis.

We should first of all emphasise the importance of qualifications to entrepreneurial activity. Formal education provides knowledge, skills, access to resources and information. In many contexts at the higher education threshold, it also stimulates innovation and creativity and promotes the integration of individuals into interpersonal networks that share information, 
Table 2 Factors of access to entrepreneurship

\begin{tabular}{ll}
\hline & Factors of access to entrepreneurship \\
\hline Qualifications & Skills and knowledge \\
& Innovation \\
\hline Previous professional experience & Of entrepreneurship \\
& Of management support \\
& In a given area of activity \\
\hline Material resources & Financial \\
& Access to credit \\
& Premises and equipment \\
\hline Family support & Financial resources \\
& Premises and equipment \\
& Human resources \\
& Support for work-family integration \\
& Family members' professional experience \\
& Family project \\
& Motivation \\
\hline Supportive public policies & Sharing experience, knowledge and projects \\
& Motivation \\
\hline Financial \\
Logistical \\
Premises and equipment \\
\hline
\end{tabular}

resources, goals and business interests. The fact is that many of the cases analysed here correspond to qualified entrepreneurs whose businesses include a strong innovatory component, and in some cases are even based on scientific elements articulated with research conducted in a university context.

Previous professional experience is also crucial to understanding the motivation to create a business. This was not the first venture into entrepreneurship for some of the entrepreneurs we interviewed, who considered their past experiences in this domain to be the foundations for learning practical and technical skills needed to create and manage their own companies. In other cases they weren't involved directly in the creation of a firm. Many of them worked with someone they were close to and was also an entrepreneur, and helped them with different aspects of the daily task of managing a company. Such working contexts also favour the development of dispositions, skills and motivation for entrepreneurship. As we have seen, in some situations working for someone else can be a platform for learning and for the gestation of entrepreneurial projects, either as a result of the positive stimulus to invest in a given area of activity, or due to the accentuated contrast with professional ambitions for the future.

Any entrepreneurial experience is necessarily based on material resources, both from a financial point of view and in terms of premises and equipment. In implementing a business idea, entrepreneurs can take a more autonomous stance if they are able to mobilise their own resources without needing outside support. In some cases - generally involving individuals with privileged social origins (in cultural and financial terms) - they made use of accumulated economic capital and/ or real estate assets to start their companies. In other situations bank loans were indispensable to the implementation of their entrepreneurial plans when it came to the initial formalisation of the business, the acquisition of equipment, the investment in workspaces and the hiring of staff. Regardless of the way in which they are obtained, material resources are a primary condition for any entrepreneurial project to become viable and to be sustainable.

Family support is also a key factor and must be taken into due consideration. To begin with, family frequently provides material support in the form of financial resources, premises and equipment. Relatives are very often mobilised as human resources for the new business, both initially to support the process of drawing up and implementing the project on a more informal basis, and then later on as part of the firm's actual workforce. Family is also an important source of support for the reconciliation of work and family life. Many of the entrepreneurs we interviewed were able to count on help from relatives in caring for their children, so as not to compromise the entrepreneurial project, especially during phases that required more of the entrepreneurs' attention and dedication. Family was also a source of motivation and a context for sharing experiences 
and knowledge. Interviewees often turned to family members with entrepreneurial experience for advice and help. Some of the entrepreneurs also had relatives as business partners, thus turning the company into a family project.

To a certain extent we also found a similar type of support in the entrepreneurs' interpersonal networks. Friends, schoolmates and colleagues at work can provide financial support, help draw up a business plan, make it easier to access workspaces or equipment, and can also become partners, thus creating a joint entrepreneurial project. In other situations, many of the interviewees had friends who were also entrepreneurs and were thus able to rely on their social capital networks for advice, experience and knowledge that not only helped them take decision, but also served as a source of motivation and inspiration.

Lastly, we cannot fail to mention the impact of support programmes, especially those linked to public policies designed to promote entrepreneurship at a local, national or European level. Entrepreneurs resort to this support in search of funding, access to premises and equipment, logistical help, as well as consultancy services from market or financial specialists to help create a business plan. In many cases these programmes also offer training and education for entrepreneurship. Although the majority of the initiatives are open to anyone who is interested, this type of support is more important and can even play a decisive part for people who are less qualified and are more disadvantaged from an economic point of view, than for qualified young entrepreneurs or those with more privileged social origins. Ultimately, public support makes it possible to compensate for the shortage or even the total absence of different types of resources.

It is important to make it clear that no one factor from the set listed above explains why a person decides to create his/ her own company. The reason is instead a combination of factors, which can vary from one individual and from one type of entrepreneurship to another. What is more, each factor can have an impact that is differentiated by the singularity of each individual case.

In conclusion, it is also important to say that while the gender dimension cuts across all these factors, its effects can be felt for example in the choice of the company's area of activity: women tended to concentrate in the areas linked to health, social services and education, while men predominated in financial activities and construction, but also in technical and scientific activities and trading. However, gender effects were also clearly present in both the emotional bond to the entrepreneurial project (identifiable above all in women entrepreneurs) and concerns about reconciling work and family life (whose responsibility is still primarily undertaken by women). Underlying these gendered differences - a situation that would deserve an article in its own right - are differentiated socialisation processes and effective inequalities in both the labour market and family relationships, which make it harder for women to gain access to entrepreneurial and managerial activities. However, these dynamics can be countered to some extent by promoting the factors for entrepreneurship listed above. This is why it is so important to develop in-depth knowledge about why people become entrepreneurs, thereby providing support initiatives with grounds that are clear as to which are the most decisive axes for fostering entrepreneurship and defining the corresponding target groups.

\section{Acknowledgement}

This work was supported by the Portuguese Foundation for Science and Technology (Ministry of Education and Science) and the Portuguese Commission for Citizenship and Gender Equality [grant number PIHM/GC/0006/2008].

\section{References}

Aldrich, H. E. (2005) Entrepreneurship. In: Smelser, N. J., Swedberg, R. (eds): The Handbook of Economic Sociology. Princeton University Press, New York. pp. 451-477.

Anderson, E. R. (2008) 'Whose name's on the awning?' Gender, entrepreneurship and the American diner. Gender, Place and Culture. 15(4), pp. 395 410. DOI: 10.1080/09663690802155611

Anderson, A., Park, J., Jack, S. (2007) Entrepreneurial social capital. Conceptualizing social capital in new high-tech firms. International Small Business Journal. 25(3), pp. 245-272. DOI: 10.1177/0266242607076526

Annink, A., den Dulk, L. D. (2012) Autonomy: the panacea for self-employed women's work-life balance?. Community, Work \& Family. 15(4), pp. 383-402. DOI: 10.1080/13668803.2012.723901

Arenius. P., Kovalainen, A. (2006) Similarities and differences across the factors associated with women's self-employment preference in the Nordic countries. International Small Business Journal. 24(1), pp. 31-59. DOI: $10.1177 / 0266242606059778$

Beham, B., Etherington, D., Rodrigues, E. (2011) Variations in work-life balance satisfaction among service sector employees. In: Back-Wiklund M, van der Lippe T, den Dulk ,L., Doorne-Huiskes, A. (eds): Quality of Life and Work in Europe. Theory, Practice and Policy. Palgrave, London, pp. 118-134.

Block, J. H., Hoogerheide, L., Thurik, R. (2013) Education and entrepreneurial choice. An instrumental variables analysis. International Small Business Journal. 31(1), pp. 23- 33. DOI: 10.1177/0266242611400470

Botha, M., Nieman, G., Vuuren, J. V. (2006) Enhancing female entrepreneurship by enabling access to skills. International Entrepreneurship and Management Journal. 2(4), pp. 479-493. DOI: 10.1007/s11365-006-0011-2

Brannon, D. L., Wiklund, J., Haynie, J. M. (2013) The varying effects of family relationships in entrepreneurial teams. Entrepreneurship Theory and Practice. 37(1), pp. 107-132. DOI: 10.1111/j.1540-6520.2012.00533.x

Bruni, A., Gherardi, S., Poggio, B. (2004) Doing gender, doing entrepreneurship. An ethnographic account of intertwined practices. Gender, Work and Organization. 11(4), pp. 406-429.

DOI: 10.1111/j.1468-0432.2004.00240.x

Bruni, A., Gheraradi, S., Poggio, B. (2005) Gender and Entrepreneurship. An Ethnographic Approach. Routledge, London.

Brush, C. G. (2008) Women entrepreneurs. A research overview. In: Casson, M., Yeung, B., Basu, A., Wadeson, N. (eds): The Oxford Handbook of Entrepreneurship. Oxford University Press, Oxford, pp.611-628. DOI: 10.1093/oxfordhb/9780199546992.003.0023

Carter. S. (2000) Improving the numbers and performance of women-owned businesses. Some implications for training and advisory services. Education and Training. 42(4-5), pp. 326-334. DOI: 10.1108/00400910010373732 
Clercq, D. D., Voronov, M. (2009) Toward a practice perspective of entrepreneurship. Entrepreneurial legitimacy as habitus. International Small Business Journal. 27(4), pp. 395-419. DOI: 10.1177/0266242609334971

Costa, A. F., Machado, F. L., Almeida, J. F. (2009) Social classes and educational assets. A transnational analysis. In: Costa, A. F., Machado, F. L., Ávila, P. (eds): Knowledge and Society. (Portugal in the European Context, vol. II). Celta, Lisbon. pp. 5-20.

Craig, L., Powell, A., Cortis, N. (2012) Self-employment, work-family time and the gender division of labour. Work, Employment and Society. 26(5), pp. 716-734. DOI: 10.1177/0950017012451642

Crompton, R. (ed.) (1999) Restructuring Gender Relations and Employment. The Decline of the Male Breadwinner. Oxford University Press, Oxford.

Crompton, R. (2006) Employment and the Family. The Reconfiguration of Work and Family Life in Contemporary Societies. Cambridge University Press, Cambridge. DOI: 10.1017/cbo9780511488962

Cruz, A. D., Howorth, C., Hamilton, E. (2013) Intrafamily entrepreneurship. The formation and membership of family entrepreneurial teams. Entrepreneurship Theory and Practice. 37(1), pp. 17-46. DOI: $10.1111 / \mathrm{j} .1540-6520.2012 .00534 . x$

Eddleston, K. A., Powell, G. N. (2012) Nurturing entrepreneurs' work-family balance. A gendered perspective. Entrepreneurship Theory and Practice. 36(3), pp. 513-541. DOI: 10.1111/j.1540-6520.2012.00506.x

García, M. C. D., Welter, F. (2011) Gender identities and practices. Interpreting women entrepreneurs' narratives. 31(4), pp. 384-404. International Small Business Journal. DOI: 10.1177/0266242611422829

Guerreiro, M. D. (1996) Famílias na Actividade Empresarial. (Families in Business Activity.) Celta, Oeiras. (in Portuguese)

Guerreiro, M. D., Pegado, E., Rodrigues, N., Saleiro, S. P. (2001) Relações Sócio-Laborais em Micro e Pequenas Empresas. (Socio-Labour Relations in Small and Medium Enterprises.) OEFP, Lisbon. (in Portuguese)

Guerreiro, M. D., Rodrigues, E. A. (2009) Work and family: what quality of life? An exploratory analysis of the services sector. In: Guerreiro, M. D., Torres, A. C., Capucha, L. (eds.): Welfare and Everyday Life. (Portugal in the European Context, vol. III). Celta, Lisbon. pp.73-106.

Guerreiro, M. D., Sümer, S., Smithson, J., Granlund, L. (2008) Becoming working mothers. Reconciling work and family at three particular workplaces in Norway, the UK, and Portugal. Community, Work \& Family. 11(4), pp. 365-384. DOI: 10.1080/13668800802361815

Guerreiro, M. D., Rodrigues, E. A., Caetano, A., Couto, A.I., Barroso, M., Alexandre, A. (2011) Género, Empreendedorismo e Qualificações. Tendências, Contextos e Experiências Individuais. (Gender, Entrepreneurship and Qualifications. Trends, Contexts and Individual Experiences.) CIESIUL, Lisbon. (in Portuguese)

Hochschild, A. (1989) The Second Shift. Working Parents and the Revolution at Home. University of California Press, Berkeley.

Howorth, C., Ali, Z. A .(2001) Family business succession in Portugal. An examination of case studies in the furniture industry. Family Business Review. 14(3), pp. 231-244. DOI: 10.1111/j.1741-6248.2001.00231.x

Howorth, C., Rose, M., Hamilton, E., Westhead, P. (2010) Family firm diversity and development. An introduction. International Small Business Journal. 28(5), pp. 437-451. DOI: 10.1177/0266242610373685

Hughes, K. D. (2003) Pushed or pulled? Women's entry into self-employment and small business ownership. Gender, Work and Organization. 10(4), pp. 33-454. DOI: 10.1111/1468-0432.00205

Kanter, R. M. (1993 [1977]) Men and Women of the Corporation. Basic Books, New York.

Kim, P. H., Aldrich, H. E. (2005) Social Capital and Entrepreneurship. Now Publishers, Delft.
Kobeissi, N. (2010) Gender factors and female entrepreneurship. International evidence and policy implications. Journal of International Entrepreneurship. 8(1), pp. 1-35. DOI: 10.1007/s10843-010-0045-y

Larty, J., Hamilton, E. (2011) Structural approaches to narrative analysis in entrepreneurship research. Exemplars from two researchers. International Small Business Journal. 29(3), pp. 220-237. DOI: $10.1177 / 0266242611401796$

Lewis, S., Doornie-Huskies, A., Reday, D., Barroso, M. (2011) The healthy organization. In: Back-Wiklund, M., van der Lippe, T., den Dulk, L., Doorne-Huiskes, A. (eds.): Quality of Life and Work in Europe. Theory, Practice and Policy. Palgrave, London. pp. 165-185.

Man, T. W. Y (2006) Exploring the behavioural patterns of entrepreneurial learning. A competency approach. Education and Training. 48(5), pp. 309-321. DOI: 10.1108/00400910610677027

Marlow, S., Henry, C., Carter, S. (2009) Exploring the impact of gender upon women's business ownership. Introduction. International Small Business Journal. 27(2), pp. 139-148. DOI: 10.1177/0266242608100487

Nabi, G., Holden, R. (2008) Graduate entrepreneurship. Intentions, education and training. Education and Training. 50(7), pp. 545-551. DOI: $10.1108 / 00400910810909018$

Patterson, N., Mavin, S. (2009) Women entrepreneurs. Jumping the corporate ship and gaining new wings. International Small Business Journal. 27(2), pp. 173-192. DOI: 10.1177/0266242608100489

Pittaway, L., Rodriguez-Falcon, E., Aiyegbayo, O., King, A. (2010) The role of entrepreneurship clubs and societies in entrepreneurial learning. International Small Business Journal. 29(1), pp. 37-57. DOI: $10.1177 / 0266242610369876$

Powell, G. N. (2010) Women and Men in Management. London: Sage.

Rasmussen, E. (2011) Understanding academic entrepreneurship. Exploring the emergence of university spin-off ventures using process theories. International Small Business Journal. 29(5), pp. 448-471. DOI: $10.1177 / 0266242610385395$

Robichaud, Y., Zinger, J. T., LeBrasseur, R. (2007) Gender differences within early stage and established small enterprises. An exploratory study. International Entrepreneurship and Management Journal. 3(3), pp. 323343. DOI: 10.1007/s11365-007-0039-y

Robson, P. J. A., Wijbenga, F., Parker, S. C. (2009) Entrepreneurship and policy. Challenges and directions for future research. International Small Business Journal. 27(5), pp. 531-535. DOI: 10.1177/0266242609338753

Taatila, V. P. (2010) Learning entrepreneurship in higher education. Education and Training. 52(1), pp. 48-61. DOI: 10.1108/00400911011017672

Thornton, P. H. (1999) The sociology of entrepreneurship. Annual Review of Sociology. 25, pp. 19-46.

Thornton, P. H., Ribeiro-Soriano, D., Urbano, D. (2011) Sociocultural factors and entrepreneurial activity. An overview. International Small Business Journal. 29(2), pp. 105-118. DOI: 10.1177/0266242610391930

Tlaiss, H. A. (2014) Women's Entrepreneurship, Barriers and Culture: Insights from the United Arab Emirates. The Journal of Entrepreneurship. 23(2), pp. 289-320. DOI: 10.1177/0971355714535307

Urbano, D., Toledano, N., Ribeiro-Soriano, D. (2011) Sociocultural factors and transnational entrepreneurship. A multiple case study in Spain. International Small Business Journal. 29(2), pp. 119-134. DOI: $10.1177 / 0266242610391934$

Zellweger, T. M., Nason, R. S., Nordqvist, M. (2012) From longevity of firms to transgenerational entrepreneurship of families. Introducing family entrepreneurial orientation. Family Business Review. 25(2), pp. 136-155. DOI: $10.1177 / 0894486511423531$ 